\title{
Lesson Study dalam Meningkatkan Ketrampilan 4C (Critical Thingking, Collaborative, Communicative dan Creative) pada Pembelajaran Sosiologi yang Terintegrasi ABS-SBK di SMAN 1 Pasaman
}

\author{
Dendy Marta Putra ${ }^{1}$, Nurlizawati Nurlizawati ${ }^{2}$ \\ ${ }^{1}$ SMAN 1 Pasaman \\ ${ }^{2}$ Universitas Negeri Padang \\ Email: dendymputra@gmail.com, liza qyuter@gmail.com
}

\begin{abstract}
Abstrak
Artikel ini menggambarkan tentang penerapan Lesson Study dalam meningkatkan ketrampilan 4C (Critical Thinking, Collaborative, Commnicative, dan Creative) pada pembelajaran sosiologi. Tuntutan kurikulum berbasis 4.0 menuntut siswa harus mampu bekerja sama, berkomunkasi, berfikir kritis dan kreatif, tuntutan ini dapat dicapai jika guru membuat pembelajaran yang dapat meningkatkan ketrampilan 4C. Dalam meningkakan kemampuan 4C dapat dilakukan dengan menerapkan kegiatan lesson study, selain itu peningkatan ketrampilan $4 \mathrm{C}$ juga harus diikuti dengan penanaman karakter yang dapat menyiapkan siswa dalam menghadapi tantangan. Metode penelitian yang digunakan adalah penelitian tindakan kelas. Hasil penelitian ini menunjukan bahwa kegiatan Lesson study merupakan bentuk pembelajaran yang meningkatkan kemampuan berfikir tingkat tinggi dan ketrampilan 4C (critical thinking, creative, collaborative, dan commnicative). Penerpaan Adat Basandi Syarak, Syarak Basandi Kitabullah (ASB-BSK) dalam membentuk karakter religius pada siswa dapat dimasukan kedalam materi pembelajaran Sosiologi menggunakan pembelajaran indirect teching, penguatan pendidikan karakter dengan penanaman nilai AlQuran dan budaya Minangkabau merupakan alternatif untuk menumbuhkembangkan karakter religius dan bermasyarakat.
\end{abstract}

Kata Kunci: Lesson Study, Ketrampilan 4C, Collaborative, Communicative, Critical Thinking dan Creative, ABS$S B K$

\begin{abstract}
This article describes the application of Lesson Study in improving the $4 C$ (Critical Thinking, Collaborative, Communicative, and Creative) skills in sociology learning. The 4.0-based curriculum demands that students must be able to work together, communicate, think critically and creatively, these demands can be achieved if the teacher makes learning that can improve $4 C$ skills. In increasing the ability of $4 C$ can be done by implementing lesson study activities, in addition to improving the skills of $4 \mathrm{C}$ must also be followed by planting characters that can prepare students to face challenges. The research method used was classroom action research. The results of this study indicate that the Lesson study activity is a form of learning that enhances high-level thinking skills and $4 C$ skills (critical thinking, creative, collaborative, and communicative). The application of Adat Basandi Syarak, Syarak Basandi Kitabullah (ASB-BSK) in shaping religious character in students can be incorporated into sociology learning materials using indirect learning learning, strengthening character education by instilling Al-Quran values and Minangkabau culture is an alternative to developing religious and social character.
\end{abstract}

Keywords: Lesson Study, 4C Skills, Collaborative, Communicative, Critical Thinking and Creative, ABS-SBK

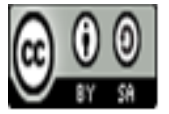




\section{Pendahuluan}

Pendidikan diera 4.0 menekankan adanya pemanfaatan teknologi dalam proses pembelajaran, dan mewujudkan generasi yang inovatif dan kreatif. Namun di tengah kuatnya arus globalisasi dan modernisasi serta perkembangan teknologi saat ini, pendidikan kita dihadapkan dengan tantangan berkembangnya paham neoliberalisme dan sekulerisme yang memberikan akses bagi generasi muda untuk bebas menganut aliran apapun, bebas berkomunkasi, bebas berpendapat dan bebas berekspresi serta bebas membina hubungan dan berkomunikasi dengan siapapun. Hal ini berpotensi merubah tatanan budaya turun temurun yang sudah ada, konsekuensinya para generasi muda akan kehilangan jati dirinya akibat tergerus oleh perkembangan zaman.

Tantangan dalam mengembangakan pendidikan berbasis teknologi ini adalah pengembangan karakter yang harus seimbang dengan nilai agama dan budaya masyarakat. Sumatera Barat merupakan daerah yang berkembang dengan mengutamakan nilai Al-Quran dan Budaya Adat Minangkabau dalam kesehariannya seperti pepatah Adat Bersendi Syarak, Syarak Bersendi Kitabullah (ABS-SBK). Tututan pendidikan di Sumatera Barat bahwa nilai budaya Minagkabau dan Al-Quran merupakan salah satu cara dalam menanamkan karakter pada siswa. Berangkat dari kondisi saat ini, harapan kedepan peserta didik bertingkah laku sesuai dengan nilainilai Al-Qur'an dan budaya alam Minangkabau. Sebagaimana pesan adat Minangkabau "nan tuo dihormati, nan ketek disayangi, samo gadang lawan baiyo", adapun budaya minang ini sudah mulai pudar karena tergeser oleh teknologi komunikasi dan inforrmasi seperti media virtual dan media sosial yang berkembang saat ini. Mereka kurang peduli dengan orang tua, guru, teman dan masyarakat, karena mereka asyik dengan dirinya sendiri.

Untuk meminimalisir terjadinya situasi yang semakin buruk lagi, Dinas Pendidikan Provinsi Sumatera Barat berusaha menemukan solusi untuk membentengi generasi muda Sumatera Barat dengan mengintegrasikan Pendidikan Al-Qur'an dan Budaya Alam Minangkabau pada semua mata pelajaran di kelas.

Penguatan pendidikan karakter harus ditumbuhkembangkan dalam pembelajaran di kelas untuk membentengi siswa dari pengaruh negatif kemajuan teknologi dan globalisasi. Keinginan kuat dinas pendidikan Sumatera Barat dalam mengintegrasikan nilai Al-Quran dan budaya Minangkabau merupakan salah satu cara untuk memperkuat karakter siswa dalam pembelajaran tanpa menghilangkan esensi pengetahuan yang harus dipelajari siswa dalam Kurikulum 2013.

Disamping penguatan karakter, siswa dihadapkan kepada era revolusi industri yang dikenal 4.0 yang menekankan ketrampilan 4C (critical thingking, collaorative, communicative, dan creative). Pendidikan abad 21 ini menekankan adanya ketrampilan 4C yang beorientasi pada HOTS (High Order Thingking) yang menekanan kemampuan berfikir tingkat tinggi.

Di abad ke 21 ini, pendidikan menjadi semakin penting untuk menjamin peserta didik memiliki keterampilan belajar dan berinovasi, keterampilan menggunakan teknologi dan media informasi, serta dapat bekerja, dan bertahan dengan menggunakan keterampilan untuk hidup (life skills). Kurikulum 2013 merupakan kurikulum yang menekankan adanya ketrampilan abad 21. Salah satu aspek penting dalam perubahan kurikulum 2013 adanya ketrampilan yang harus dimiliki oleh peserta didik yaitu ketrampilan 4C (Critical thinking, Communication, Collaborative dan Creative).

Kurang terasahnya kemampuan siswa dalam komunikasi dan bekerja sama merupakan sebuah permasalahan penting yang menggangu proses pembelajaran. Pembelajaran sosiologi merupakan pembelajaran yang menuntut aspek kognitif, dalam hal ini sangat memerlukan ketrampilan 4C (Critical thinking, Communication, Collaborative dan Creative)

Penggunaan proses Lesson Study dengan program-program pengembangan yang profesional tersebut merupakan wahana untuk mengembalikan guru kepada budaya mengajar yang proporsional. Pembelajaran dengan menggunakan kegiatan Lesson Study tentunya dapat membantu guru dalam dalam memperbaiki proses pembelajaran, agar siswa dapat menguasai ketrampilan critical thingking, creative, communication dan collaborative salah satunya dapat difasilitasi melalui tutor teman sebaya.

Kurikulum 2013 menekankan adanya keseimbangan kognitif, afektif dan psikomotor pada siswa. Kognitif yang mengharuskan siswa memiliki kemampuan berfikir tingkat tinggi (HOTS), 
afektif merupakan karakter yang diharapkan ada pada diri siswa, serta ketrampilan $4 \mathrm{C}$ yang harus dikuasai. Keseimbangan ketiga aspek ini dapat dilakukan dengan adanya pengintegrasian nilai AlQuran dan budaya Minangkabau dalam kegiatan Lesson study. Lesson study merupakan bentuk kegiatan yang menumbuhkembangkan kebiasaan positif siswa dalam berfikir kritis, bekerja sama, berkomunikasi dan mengembangkan kreativitas.

Pembelajaran Sosiologi di SMA 1 Pasaman telah menggunakan RPP yang mengintegrasikan nilai Al-Quran dan Budaya Minangkabau, dan dalam rangka meningkatkan ketrampilan 4C telah diterapkan kegiatan Lesson study dengan menggunakan model tutor teman sebaya. Siswa dalam kegiatan ini diharuskan untuk dapat bekerjasama, berfikir kritis, berkomunikasi dan berkerasi. Ketrampilan ini melahirkan membuat siswa untuk terlatih untuk memperoleh pengetahuan berfikir tingkat tinggi.

Berdasarkan latar belakang masalah yang dikemukan maka penulis menulis artikel ilmiah ini dengan judul "Lesson Study dalam Meningkatkan Ketrampilan 4C (Critical Thingking, Collaborative, Communicative dan Creative) pada Pembelajaran Sosiologi yang Terintegrasi ABS-SBK".

Lesson study merupakan suatu pendekatan peningkatan kualitas pembelajaran yang awal mulanya berasal dari jepang. Di Negara tersebut, kata atau istilah itu lebih popular dengan sebutan Jugyokenkyu. Lesson study dikembangkan oleh Makoto Yoshida". Lesson study adalah model pembinaan (pelatihan) profesi pendidik melalui pengkajian pembelajaran secara kolaboratif dan berkelanjutan berlandaskan prinsip-prinsip kolegialitas dan mutual learning untuk membangun komunitas belajar (Sumar Hendayana, dkk, 2009: 5). Selain itu Styler dan Hiebert (Susilo, 2009: 3) mengatakan bahwa: Lesson study adalah suatu proses kolaboratif pada sekelompok guru ketika mengidentifikasikan masalah pembelajaran, merancang suatu skenario pembelajaran (yang meliputi kegiatan mencari buku dan artikel mengenai topik yang akan diajarkan); membelajarkan peserta didik sesuai dengan skenario (salah seorang guru melaksanakan pembelajaran sedangkan yang lain mengamati), mengevaluasi dan merevisi skenario pembelajaran, membelajarkan lagi skenario pembelajaran yang telah direvisi, mengevaluasi lagi pembelajaran dan membagikan hasilnya dengan guru-guru lain (mendiseminasikannya).

Menurut Alwi (2009) ada pengaruh yang signifikan dari metode tutor teman sebaya terhadap motivasi belajar matematika siswa SMA. Hal ini berarti bahwa penerapan metode pembelajaran tutor sebaya akan meningkatkan motivasi belajar matematika siswa SMA. Tutor teman sebaya adalah perekrutan salah satu mahasiswa guna memberikan satu per satu pengajaran kepada mahasiswa lain, dalam menyelesaikan tugas yang diberikan melalui partisipasi peran tutor dan tutee. Tutor memiliki kemampuan lebih dibandingkan tutee, tapi pada beberapa variasi tutorial jarak pengetahuan yang dimiliki antara tutor dan tutee minimal (Roscoe \& Chi, 2007).

Pembelajaran dengan memanfaatan kan teman sebaya yang lebih paham terhadap materi meruupakan cara yang efektif dalam memudahkan komunikasi antar siswa. Menurut Zuraidah (2003) mengatakan bahwa, pembelajaran dengan memanfaatkan tutor sebaya dapat membantu rekan sebaya dalam aspek akademis, emosi disiplin. Dengan bantuan tutor sebaya pembelajaran akan lebih efektif, komunikatif dan efisien karena bahasa tutor lebih mudah dipahami. Dengan bantuan tutor sebaya ini peserta didik dijadikan sebagai subjek pembelajaran yaitu peserta didik yang diajak untuk dijadikan tutor atau sumber belajar dan tempat bertanya bagi teman sejawatnya. Bahasa yang digunakan mudah dipahami dan hubungan interpersonal antara teman sejawat terjalin dengan baik, sehingga terjadi transakasi pembelajaran yang efektif, aktif, inovatif dan komunikatif.

"Adat Basandi Syarak Syarak Basandi Kitabullah" adalah sebuah adagium yang dijadikan sebagai landasan filosofi hidup kemasyarakatan orang Minangkabau sejak berabad-abad yang lalu. Yang dimaksud dengan syarak disini adalah syari'at atau agama Islam yang datang menyusul setelah orang Minang- kabau memiliki adat, sedangkan yang dimaksud dengan Kitabullah disini ialah Al-Qur'an yang menjadi sumber pokok utama ajaran Islam. Sebelumnya konon orang Minangkabau me- miliki landasan falsafah hidupnya: "Adat basandi Alua jo Patuik". Alua adalah alur atau aturan-aturan yang lazim sedangkan patuik adalah sesuatu yang pantas sesuai dengan akal sehat dan kehalusan budi. Maksudnya, orang Minang harus dapat meletakkan sesuatu pada tempatnya yang tujuannya adalah untuk menciptakan keadilan dan sekaligus menghindari 
persengketaan antara sesama warga masyarakat sehingga tercipta kehidupan yang rukun dan damai. Dengan kedatangan agama Islam ke Minangkabau dan setelah menempuh proses serta perjuangan yang sangat panjang didapatilah sebuah kesepakatan antara tokoh-tokoh adat dan kaum ulama dalam sebuah keputusan yang dikenal dengan "Kesepakatan Bukit Marapalam " sehingga lahir ungkapan: "Adat Basandi Syarak-Syarak Basandi Kitabullah" (ABS- SBK). Kemudian diteruskan dengan ungkapan: "Syarak Mangato, Adat Mamakai" seperti tertuang dalam pepatah: Gantang di bodi Caniago, Cupak dijadikan ka sukatan, Adat mamakai syarak mangato, Ujuik satu balain jalan. Maksudnya, apa yang dititahkan oleh syarak diterapkan melalui adat. Misalnya, Islam mengajarkan umatnya agar berkata atau berbicara dengan sopan dan arif bijaksana sesuai dengan situasi dan kondisi lawan bicara, lalu diterjemahkan ke dalam pepatah adat dengan istilah "Kato nan Ampek". Yakni: Kato Mandaki kepada yang lebih tua, Kato Mandata kepada teman sama besar, Kata Manurun kepada yang lebih muda/kecil, dan Kata Malereng yaitu kata berkias misalnya antara mamak rumah dengan urang sumando atau antara mintuo jo minantu.

Sosiologi juga memungkinkan peserta didik mulai mengenal nilai-nilai luhur dan karakter positif yang berkembang diberbagai budaya bangsa, belajar menghargai, dan bahkan berupaya menirunya. Tidak dapat dipungkiri bahwa hal tersebut memungkinkan masuknya berbagai hal negatif ke bangsa ini. Oleh karena itu, nilai-nilai kearifan lokal seperti budaya, dan keagamaan yang lebih dikenal dengan Adat Basandi Syara', Syara' Basandi Kitabullah (ABS-SBK) Adat Mamakai Syara' mangato, alam takambang jadikan guru" di Sumatera Barat perlu diintegrasikan kedalam pembelajaran Sosiologi. Sehingga motto " Think Globally, Act Locally" perlu dimasukkan ke dalam materi pembelajaran. (Dinas Pendidikan Pemprov Sumatera Barat, 2018: 17)

\section{Metode Penelitian}

Penelitian ini merupakan penelitian tindakan kelas (action research) yang diselenggarakan secara kolaboratif dengan guru yang kelasnya dijadikan kancah penelitian tindakan kelas ini. Subjek penelitian ini adalah mahasiswa yang terdaftar dalam mata kuliah perencanaan pengajaran Sosiologi-Antropologi. Menurut Anas Yasin (2011: 6) penelitian tindakan kelas memberikan ketrampilan kepada guru dalam memecahkan masalah khusus yang berkenaan dengan kelasnya. Dengan menggunakan prosedur penelitian, guru yang meneliti dapat menghadapi tantangan di dalam pembelajaran mereka sendiri.

PTK selain bertujuan untuk meningkatkan aktivitas pembelajaran matakuliah perencanaan pengajaran Sosiologi-Antropologi, juga untuk meningkatkan kinerja guru dalam proses pembelajaran. Penelitian Tindakan Kelas ini dilakukan dengan mengintegrasikan Lesson Study. Penelitian dilakukan dalam 2 siklus, di mana dalam setiap siklus terdapat empat tahap, yaitu perencanaan, pelaksanaan, observasi, dan refleksi. Pada setiapopen class dilakukan Lesson Study yang meliputi tahapan plan, do, dan see. Kehadiran peneliti dalam penelitian ini adalah sebagai observer yang merancang kegiatan pembelajaran atau tindakan yang dilakukan bersamasama dengan tim lesson study dan guru model diperankan guru yang mengajar mata pelajaran Sosiologi. Berdasarkan tujuan penelitian yang akan menggambarkan implementasi Lesson Study dalam meningkatkan ketrampilan 4C siswa dalam mata pelajaran Sosiologi. Rencana tindakan yaitu gambaran tentang langkah-langkah ril yang akan dalam penelitian. Menurut Lewin (1946) ada 4 tahap yang dilalui dalam penelitian tindakan kelas ini, yaitu: (1) Perencanaa, (2) Pelaksanaan, (3) Pengamatan, (4) Refleksi.

\section{Hasil dan Pembahasan}

Berdasarkan penelitian yang suadah dilakukan di SMA Negeri 1 Pasaman yang mana penelitian ini terdiri dari dua siklus dengan mengkolaborasikan kegiatan lesson study dalam pembelajaran sosiologi dengan pengintegrasian ABS-SBK untuk penguatan pendidikan karakter siswa, yang masing-masing siklus terdiri dari tahapan persiapan dan pelaksanaan.

Berdasarkan data yang diperoleh peneliti dari pelaksanaan observasi terhadap aktivitas ketrampilan berkomunikasi yang dilakukan oleh siswa dengan metode tutor teman sebaya dalam kegiatan lesson study dapat diketahui tingkat aktivitas siswa. Apakah aktivitas siswa rendah, cukup, 
tinggi atau sangat tinggi, sehingga dapat diketahui peningkatan aktivitas yang diharapkan. Aktivitas siswa pada tabel dapat diukur secara kualitatif dan kuantitatif. Untuk menentukan kriteria tersebut dipakai kriteria yang dikemukakan oleh Arikunto (1991: 71), yaitu:
a. $80-100$
b. $60-80$
: sangat tinggi
c. $40-60$
: tinggi
d. $20-40$
: cukup
e. $0-20$
: rendah

Kriteria siswa yang aktif pada siklus I masih rendah, sudah mulai menampakkan keaktifan dalam belajar, namun peneliti belum merasa pada batas yang diharapkan., karena pada siklus I masih ada siswa yang belum aktif berkomunikasi dalam proses pembelajaran. Maka penulis merasa perlu melanjutkan ke siklus II. Pada siklus pertama ketrampilan komunikasi siswa kelas XI IPS 5 masih sekitar 55, 18\% yang dapat kita kategorikan bahwa dikelas ini siswa cukup memilki ketrampilan berkomunikasi.

Metode tutor teman sebaya yang dipraktekan dalam pembelajaran ini mampu meningkatkan keterlibatan siswa dalam bekomunikasi. Karena tutor teman sebaya ini memotivasi siswa-siswa dengan bantuan temannya yeng memiliki pengetahuan yang lebih. Kelebihan dari menggunakan tutor teman sebaya ini secara psikologis siswa menjadi lebih senang belajar, karena tidak begitu berjarak dengan tutornya. Karena tutornya adalah temannya sendiri, hal ini memudahkan siswa kelas XI IPS 5 untuk berkomunikasi dalam proses pembelajaran.

Secara keseluruhan pada siklus I dan siklus II terjadi peningkatan ketrampilan berkomunikasi pada siklus II. Rata-rata kenaikan persentase rata-rata siklus I dengan siklus II dengan rata-rata naik dari $55,18 \%$ menjadi $67.59 \%$, berikut gambar kegiatan pembelajaran.

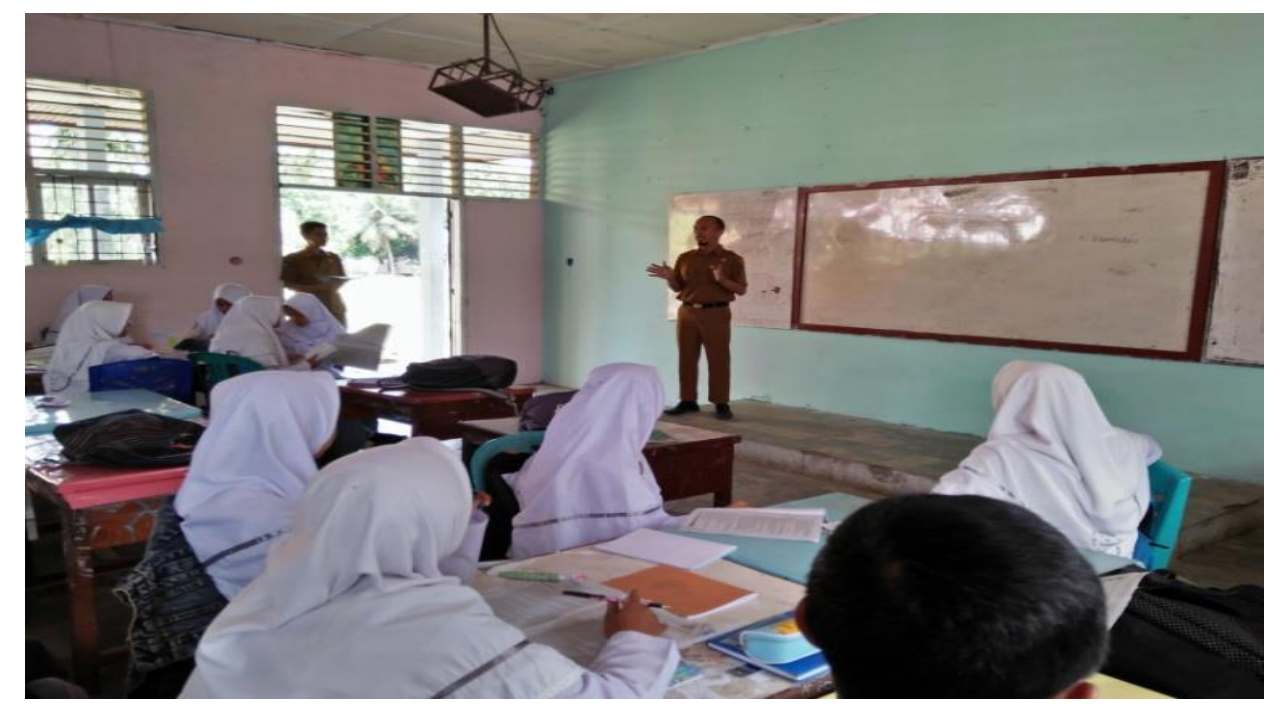

Gambar 1. Peneliti sedang Melaksankan Pembelajaran di Kelas

Menurut Zuraidah (2003) mengatakan bahwa, pembelajaran dengan memanfaatkan tutor sebaya dapat membantu rekan sebaya dalam aspek akademis, emosi disiplin. Dengan bantuan tutor sebaya pembelajaran akan lebih efektif, komunikatif dan efisien karena bahasa tutor lebih mudah dipahami.

Penggunaan model pembelajaran tutor sebaya diharapkan dapat membantu siswa dalam penerimaan materi pelajaran. Model pembelajaran ini dapat juga membantu guru untuk meningkatkan keaktifan siswa di dalam kegiatan pembelajaran karena dengan model ini siswa dituntut untuk lebih aktif dalam kegiatan pembelajaran, dan dapat memotivasi siswa terutama dalam kegiatan pembelajaran sosiologi.

Aktivitas ketrampilan berkomunikasi yang dilakukan oleh siswa dengan metode tutor teman sebaya dalam kegiatan lesson study dapat diketahui tingkat aktivitas siswa. Kemampuan bekerjasama/collaborative siswa dengan menggunakan metode tutor teman sebaya melalui 
kegiatan lesson study lebih terlihat, karena siswa akan bekerja sama dengan siswa yang lain dalam menyelesaikan tugas kelompok yang diberikan oleh guru model.

Peningkatan kemampuan bekerja sama siswa kelas XI IPS 5 pada siklus 149,37\% tergolong cukup, pada siklus ke 2 siswa lebih mampu bekerja sama dengan baik, hal ini dapat dilihat dari persentase collaborative yang sebesar 70,51\% (baik).

Ketrampilan collaborative merupakan ketarampilan yang diharapkan ada pada siswa saat ini, karena dunia kerja mengharapkan adanya kemmapuan untuk bisa bekerjasama dengan orang lain. Kolaborasi dalam proses pembelajaran merupakan suatu bentuk kerjasama dengan satu sama lain saling membantu dan melengkapi untuk melakukan tugas-tugas tertentu agar diperoleh suatu tujuan yang telah ditentukan. Dalam mengembangkan ketrampilan collaborative di kelas XI IPS 5 SMAN 1 Pasaman, tidak terlepas dari kerjasama guru dalam membuat plan pembelajaran yang mengutamakan adanya kerjasama kelompok dengan menggunakan metode tutor teman sebaya.

Peningkatan kemampuan siswa dalam berkomunikasi dan berkolaborasi merupakan tujuan utama dalam penggunaan metode tutor teman sebaya, yang dipraktikan dalam kegiatan lesson study. Kegiatan lesson study ini lebih memudahkan guru dalam merancang pembelajaran secara bersama-sama, dan menemukan solusi terhadap masalah yang didapatkan dikelas.

Pelaksanaan lesson study dengan tutor teman sebaya di kelas XI IPS 5 dapat meningkatkan kemampuan berkomunikasi dan berfikir kritis. Penerapan nilai Al-Quran dengan budaya Minangkabau untuk menguatkan pendidikan karakter siswa melalui pembelajaran secara tidak langsung (indirect teaching). Nilai-nilai Al-Quran dimasukkan dalam penyampaian materi pembelajaran sosiologi sebagai pembentuk karakter yang religius.

Pembelajaran dengan kegitan lesson study dapat meningkatkan ketrampilan 4C dan meningkatkan kemampuan berfikir tingkat tinggi, karena mellaui lesson study guru dibebaskan dalam membuat desain mind maaping yang sesuai dengan kondisi kelas. Dalam hal ini pelaksanaan lesson study diintegrasikan dengan penerapan nilai Al-Quran pada materi konflik di kelas XI IPS 5 yaitu surat Ali Imran, surat 103 yang artinya:

"Dan berpeganglah kamu semuanya pada tali (agama)Allah, dan janganlah kamu bercerai berai dan ingatlah akan nikmat Allah kepadamu ketika kamu dahulu (masa jahiliyah) bermusuhmusuhan, maka Allah mempersatukan hatimu, lalu menjadilah kamu karena nikmat Allah, orang-orang yang bersaudara; dan kamu telah beradaditepi jurang neraka, lalu Allah menyelamatkan kamu dari padanya. Demikianlah Allah meneranngkan ayat-ayatNyakepadamu, agar kamu mendapat petunjuk"

Nilai Al-Quran ini disampaikan dalam proses pembelajaran agar dapat membentuk sikap religius siswa yang berpengaruh pada karakter siswa. Nilai-nilai Al-Quran ini mengandung bahaya terjadinya konflik dan betapa orang beriman akan diberi nikmat jika tidak berkonflik. Melalui pembelajaran indirect teaching siswa secara tidak langsung dapat memahami nilai agama dan solusi dari konflik. Sehingga ada kesimbangan antara materi dan nilai-nilai karakter yang akan ditanam pada diri siswa.

Penananam nilai budaya Minangkabau pada siswa pada materi konflik sosial, salah satu nilai yang berkaitan dengan konflik yaitu

"Pucuak pauah sadang tajelo, panjuluak buah lagundi, nak jauah silang sangketo, pahaluih baso jo basi"

Maknanya:

Agar terjauh dari silang sengketa dalam pergaulan memerlukan sikap, sopan santun, saling menghargai satu sama lain. Di ibaratkan "kabukik barangin rangin, bakelok jalan ka kuranji, dek rancak urang tak ingin, budi baiak nan dicari".

Konflik dalam sosiologi berupa pertikaian, percekcokan serta permasalahan sebagai suatu proses sosial individu atau kelompok yang berusaha memenuhi tujuannya dengan jalan menantang pihak lawan yang disertai dengan ancaman dan kekerasan. Nilai Al Qur'an dan nilai budaya Minang Kabau disampaikan guru pada kegiatan inti ketika menjelaskan bahaya konflik dan kekerasan. Dengan menyampaikan QS Ali Imran 103 diharapkan peserta didik dapat lebih memahami betapa pentingnya persatuan dan kesatuan dalam mewujudkan keharmonisan sehingga masyarakat terhindar dari konflik sosial. 
Penguatan pendidikan karakter dengan penanaman nilai Al-Quran dan budaya Minangkabau merupakan alternatif untuk menumbuhkemangkan karakter religius dan bermasyarakat. Nilai-nilai budaya daerah akan lebih mudah dipahami, maka dari itu peran Adat Bersendi Syarak, Syarak Basandi Kitabullah (ASB-SBK) dalam menanamkan karakter pada mata pelajaran Sosiologi sangatlah penting dan solutif.

\section{Kesimpulan}

Kegiatan Lesson study merupakan bentuk pembelajaran yang meningkatkan kemampuan berfikir tingkat tinggi dan ketrampilan 4C (critical thinking, creative, collaborative, dan commnicative). Dalam penguatan pendidikan karakter pada siswa dapat dilakukan melalui peneriapan nilai AlQuran dan budaya Minangkabau, sering juga disebut dengan Adat Basandi Sysrak, Syarak Basandi Kitabullah (ASB-BSK).

Penerpaan Adat Basandi Sysrak, Syarak Basandi Kitabullah (ASB-BSK) dalam membentuk karakter religius pada siswa dapat dimasukan kedalam materi pembelajaran Sosiologi menggunakan pembelajaran indirect teching. Penguatan pendidikan karakter dengan penanaman nilai Al-Quran dan budaya Minangkabau merupakan alternatif untuk menumbuhkembangkan karakter religius dan bermasyarakat. Nilai-nilai budaya daerah akan lebih mudah dipahami, maka dari itu peran Adat Bersendi Syarak, Syarak Basandi Kitabullah (ASB-SBK) dalam menanamkan karakter pada mata pelajaran Sosiologi sangatlah penting dan solutif.

Dalam rangka peningkatan penguasaan ketrampilan 4C, berfikir tingakat tinggi (HOTs) guru diharapkan mampu mengembangkan metode pembelajaran yang melibatkan keaktifan siswa. Penguatan pendidikan karakter pada siswa dapat dilakuakn dengan mengutamakan nilainilai keagamaan dan nilai-nilai kebudayaan lokal.

\section{Daftar Pustaka}

Anas Yasin. (2011). Penelitian Tindakan Kelas: Tuntunan Praktis. Padang: Bung Hatta University Press.

Alwi, M. (2009). Pengaruh metode tutor sebayaterhadap motivasi dan prestasi belajar matematika siswa SMA. Tesis. Universitas Gadjah Mada.

Deny Setiawan dan Herawati Susilo. (2015). Peningkatan Keterampilan Metakognitif Mahasiswa Program Studi Biologi Melalui Penerapan Jurnal Belajar Dengan Strategi Jigsaw Dipadu Pb1 Berbasis Lesson Study Pada Matakuliah Biologi Umum. Prosiding Seminar Nasional Pendidikan Biologi 2015. Semarang: Universitas Negeri Semarang

Farida Nurhasanah. (2012). Membangun Keaktifan Mahasiswa Pada Proses Pembelajaran Mata Kuliah Perencanaan Dan Pengembangan Program Pembelajaran Matematika Melalui Pendekatan Konstrutivisme Dalam Kegiatan Lesson Study. Surakarta: Universitas Sebelas Maret Surakarta.

Maghfiroh, Besty. (2012). Pengaruh Strategi Pembelajaran Kooperatif Learning Model Tutor Sebaya Terhadap Minat dan Hasil Belajar Matematika Kelas V Madrasah Ibtidaiyah Darul Huda Ngaglik Bandulan Sleman Yogyakarta. Yogyakarta: UIN Sunan Kalijaga.

Laila Nursafitri. (2015). Peningkatan Kualitas Pembelajaran Melalui Lesson Study. Lampung: Sekolah Tinggi Agama Islam (STAI) Darussalam Lampung.

Lewis, Catherine C. (2002). Brief Guide to Lesson Study. Excerpted from Catherine Lewis, "Lesson Study: A Handbook for Teacher-Led Improvement of Instruction. Philadelphia: Research for Better Schools.

Podhorsky, C. \& Moore, V. (2006). Issues in Curriculum: Improving Instructional PracticeThrough Lesson Study.http://www.lessonstudy.net.

Roscoe, R.D., \& Chi, M.T.H. (2007). Understandingtutor learning: Knowledge building and knowledgetelling in peer tutors' explaination and questions. Review of Education Research, 77 (4): 534-574.

Soekanto, Soerjono. (2007). Sosiologi Suatu Pengantar. Jakarta: PT.Rajagrafindo Persada

Sumar, Hendayana, 2006, Lesson Study Suatu Strategi Untuk Meningkatkan Keprofesionalan Pendidikan, Bandung: UPI Press. 
Dendi Marta Putra, Nurlizawati Nurlizawati Lesson Study dalam meningkatkan Keterampilan $4 C$ (Critical Thinking, Collaborative, Communivative, dan Creative) pada Pembelajaran Sosiologi yang Terintegrasi ABS-SBK di SMAN 1 Pasaman

Susilo, H. (2006). Apa dan Mengapa Lesson Study Perlu Dilakukan untuk Meningkatkan Profesionalisme Guru dan Dosen MIPA. Makalah. Disajikan dalam Seminar Peningkatan Profesionalisme Guru dan Dosen MIPA melalui Lesson Study, di Singaraja, 25 November 2006.

Susilo, Herawati, et. al., (2009), Lesson Study Berbasis Sekolah, Malang: Bayu Media.

Zuraidah, A. R. (2003). Pembimbing rekan sebaya satu pendekatan logikal. Tersedia pada: http//www.geocities.com/prshm/stu-pendekatanlogic.html. Di akses pada tanggal 18 desember 2017. 